CLINICAL STUDY

\title{
Allelic variations of RANKL/OPG signaling system are related to bone mineral density and in vivo gene expression
}

\author{
István Takács $^{1}$, Áron Lazáry ${ }^{1,2}$ János P Kósa $^{1}$, János Kiss ${ }^{3}$, Bernadett Balla ${ }^{1}$, Zsolt Nagy ${ }^{1}$, Krisztián Bácsi ${ }^{1}$, \\ Gabor Speer ${ }^{1}$ and Péter Lakatos ${ }^{1}$ \\ ${ }^{1} 1$ st Department of Internal Medicine, Semmelweis University, Korányi S. u. 2/a, Budapest H-1083, Hungary, ${ }^{2}$ National Center for Spinal Disorders, \\ Buda Health Center, Királyhágó u 1-3, Budapest H-1113, Hungary and ${ }^{3}$ Department of Orthopedics, Semmelweis University, Karolina út 27, Budapest \\ H-1113, Hungary \\ (Correspondence should be addressed to I Takács; Email: takist@bel1.sote.hu) \\ (I Takács and Á Lazáry contributed equally to this work)
}

\begin{abstract}
Objective: Receptor activator of nuclear factor- $\kappa \mathrm{B}$ ligand/osteoprotegerin (RANKL/OPG) signaling system plays a crucial role in the regulation of bone resorption. Polymorphic variations in the genes may have an influence on gene expression and bone metabolism. In the present study, we aimed to investigate the influence of RANKL/OPG allelic variations on the in vivo human gene expression of five genes, bone mineral density (BMD), and fracture incidence in Hungarian postmenopausal women. Methods: Three hundred and sixty postmenopausal women $(61.6 \pm 7.9$ years $)$ were genotyped. All together, five single nucleotide polymorphisms (SNPs) in the two genes have been investigated. In addition, bone samples from 17 examined subjects were acquired for gene expression studies. Bone densities and fracture data have also been collected.

Results: All two SNPs in OPG gene and three SNPs in RANKL gene showed correlation with BMD. Haplotype analysis of these genes gave similar results. The 'CCT' haplotype of RANKL promoter region, which was associated with decreased BMD, exhibited a significantly upregulated expression of RANKL mRNA, while the other haplotypes of RANKL or OPG 15 genes did not. No correlation between genetic variations and fracture data was found.

Conclusion: We have demonstrated associations between RANKL and OPG haplotypes and BMD as well as between RANKL haplotypes and in vivo RANKL expression in a Hungarian postmenopausal population. Moreover, we have found a new RANKL haplotype associating with reduced BMD and increased in vivo RANKL expression in human bone tissue.
\end{abstract}

European Journal of Endocrinology 162 423-431

\section{Introduction}

Osteoporosis (OP) is a systemic skeletal disease characterized by low bone mass and microarchitectural deterioration of bone tissue, with a consequent increase in bone fragility and susceptibility to fractures (1). The major determinants of the risk for OP in later life are peak bone mass achieved during adulthood and the subsequent rate of bone loss (2). The peak bone mineral density (BMD) of adult women is mostly determined genetically (3). Twin studies in postmenopausal and elderly women also support a persistent and significant genetic influence on bone mass in later life (4). OP is a complex disease that is presumably influenced by multiple genes (5). Identification of genes that affect postmenopausal OP will permit early detection of individuals who are at risk for OP and early institution of preventive measures.

TNFRSF11A/TNFSF11/TNFRSF11B signaling system plays a crucial role in the regulation in bone resorption
$(6,7)$. The receptor activator of nuclear factor- $\mathrm{KB}$ (TNFRSF11A/RANK) and its ligand TNFSF11 are the key proteins in osteoclastogenesis (8). The TNFRSF11A/ TNFSF11 interaction is negatively controlled by TNFRSF11B (osteoprotegerin (OPG)), a known inhibitor of osteoclastogenesis, which acts as a soluble decoy receptor for TNFSF11 $(8,9)$.

In vivo studies confirm the bone-protective role of TNFRSF11B. TNFRSF11B knockout mice developed severe OP $(10,11)$, while overexpression of TNFRSF11B in transgenic mice resulted in osteopetrosis (6). Polymorphisms of the TNFRSF $11 B$ gene may contribute to the genetic regulation of bone mass as suggested by several recent publications, but the results are somewhat contradictory (12-16). The ambiguous results include the frequently investigated rs3102735 single nucleotide polymorphism (SNP) effects on BMD and fracture risk $(14,17)$. Recently, an association between BMD and SNPs of OPG gene has been demonstrated during a genome-wide screening $(18,19)$. 
TNFSF11 expressed by osteoblasts directly activates cells of osteoclast lineage by connecting to the membrane receptor TNFRSF11A (20). TNFSF11-deficient mice show severe osteopetrosis with no tartrate-resistant acid phosphatase-positive osteoclasts (21). Soluble form of TNFSF11 rapidly induced hypercalcemia and bone loss (22). SNPs identified in the promoter and $5^{\prime}$ UTR region of the gene have shown an association with BMD $(10,23-25)$. The quantitative trait analysis also found a correlation between BMD, low-trauma fractures, and genomic regions of TNFSF11 (19).

Based on previous data, we hypothesized that the allelic variations of the TNFRSF $11 B$ and TNFSF 11 genes - individually, in haplotypes, and in interaction - are associated with both osteoporotic phenotypes and in vivo gene expressions of the two genes. Our study was aimed at investigating the influence of TNFRSF11B/TNFSF11 gene allelic variations on the in vivo human gene expression of these genes, BMD, and fracture incidence in Hungarian postmenopausal women.

\section{Materials and methods}

\section{Study population and BMD measurement}

Three hundred and sixty Hungarian unrelated postmenopausal women were recruited into the study through our metabolic bone disease outpatient clinic. One thousand and eight patients presenting to our clinic between January and July 2005 were invited to participate in our study. All subjects underwent physical examination and completed a detailed questionnaire on family and medical histories as well as on lifestyle habits including calcium intake. The calcium intake was determined by a validated European questionnaire (26). BMD values at the lumbar spine (L2-L4) and total hip were measured using a Lunar Prodigy DXA (GE Medical Systems, Diegem, Belgium). Covariance was below $1 \%$ at both sites. OP was defined according to the WHO criteria, i.e. T-score less than -2.5 S.D. at any measured site. Detailed fracture history was obtained from each subject. Nonvertebral osteoporotic fracture was defined as low-trauma fractures after the age of 45 years excluding fractures of the face, skull, fingers, toes, and spine. Vertebral compression fractures were not investigated in this study. Exclusion criteria were history of bone, metabolic or endocrine diseases; any chronic illness; previous hormone-replacement or steroid therapy or any medication known to influence bone metabolism; premature menopause (before 40 years of age); and alcohol consumption (more than two units/day). Subjects with biochemical abnormalities such as increased level of serum alkaline phosphatase, TSH, and parathyroid hormone, or reduced level of $25-\mathrm{OH}$ vitamin $\mathrm{D}_{3}(<30 \mathrm{ng} / \mathrm{ml})$ were not included in the study. The population characteristics are presented in Table 1 . The study was approved by the local ethics
Table 1 Characteristics of study population $\left(n=353^{\mathrm{a}}\right)$.

\begin{tabular}{ll}
\hline Variable & Mean \pm s.D. \\
\hline Age (years) & $61.6 \pm 7.9$ \\
Menopausal age (years) & $13.5 \pm 8.3$ \\
Body mass index $\left(\mathrm{kg} / \mathrm{m}^{2}\right)$ & $27.6 \pm 4.5$ \\
Smokers & $45(12.5 \%)$ \\
Alcohol consumption & $16(4.44 \%)$ \\
Calcium intake $(\mathrm{mg} / \mathrm{day})$ & $642 \pm 113$ \\
Serum $25-\mathrm{OH}$ vitamin $\mathrm{D}_{3}(\mathrm{ng} / \mathrm{ml})$ & $44.6 \pm 6.7$ \\
Lumbar spine $\mathrm{BMD}\left(\mathrm{g} / \mathrm{cm}^{2}\right)$ & $0.887 \pm 0.176$ \\
Total hip BMD $\left(\mathrm{g} / \mathrm{cm}^{2}\right)$ & $0.785 \pm 0.168$ \\
Subjects with osteoporosis at either site & $198(55 \%)$ \\
Subjects with nonvertebral osteoporotic & $76(21.5 \%)$ \\
$\quad$ fractures &
\end{tabular}

${ }^{a}$ This table shows the parameters of the final study cohort. Seven subjects were excluded from the statistical analyses.

${ }^{\mathrm{b}}$ More than one drink per week but less than one drink per day.

committee, and written informed consent was obtained from all participants.

Seventeen of the studied subjects had recently undergone total hip arthroplasty due to osteoarthrosis. During the operation, nonosteoarthritic bone tissue samples from the femoral neck were collected from these patients for gene expression analyses. This study was separately approved by the ethics committee, and separate informed consent was obtained from these women.

\section{Genotyping}

Two SNPs in TNFRSF11B (rs1564858 and rs3102735 (A163G)) and three SNPs in TNFSF11 (rs9533156 (T643C), rs9525641 (T290C), and rs3742257) were genotyped in this study (Table 2). The rationale for selecting the SNPs was that either these polymorphisms had been suggested to play a role in bone metabolism or they had been shown to be located physically close to one of the previously examined SNPs. In this way, we hoped to identify haplotypes demonstrating a strong relationship with gene expression and BMD as well as with fracture incidence.

Genomic DNA was extracted from venous blood samples using High Pure PCR Template Purification kit (Roche). DNA quality and quantity were determined using NanoDrop B-100 spectrophotometer (NanoDrop Technologies, Wilmington, DE, USA). Genotypes were determined using a GenomeLab SNPstream Genotyping System (Beckman Coulter, Fullerton, CA, USA) at the SNP Core Facility of Semmelweis University. The automated, ultra-high-throughput genotyping system utilizes multiplexed PCR in conjunction with taggedarray, multiplexed, single-base primer extension technology. PCR primers and tagged extension primers were designed on Autoprimer.com, the web-based primer design tool of Beckman Coulter (http://www. autoprimer.com). Ten random samples were genotyped in three parallel runs for testing technical errors. 
Table 2 Selected single nucleotide polymorphisms (SNPs) for genotyping.

\begin{tabular}{|c|c|c|c|c|c|c|c|}
\hline Gene & SNP number & Alleles & SNP position & SNP site & Success (\%) & HW & MAF \\
\hline \multirow[t]{2}{*}{ TNFRSF11B } & rs1564858 & $\mathrm{A} / \mathrm{G}$ & chr8:120014347 & Intron & 99.7 & 0.069 & 0.140 \\
\hline & rs3102735 & $\mathrm{C} / \mathrm{T}$ & chr8:120034251 & Promoter & 100 & 0.954 & 0.146 \\
\hline \multirow[t]{3}{*}{ TNFSF11 } & rs9533156 & $\mathrm{C} / \mathrm{T}$ & chr13:42045671 & Promoter & 99.4 & 0.396 & 0.460 \\
\hline & rs9525641 & $\mathrm{C} / \mathrm{T}$ & chr13:42046024 & Promoter & 99.4 & 0.453 & 0.459 \\
\hline & rs3742257 & $\mathrm{C} / \mathrm{T}$ & chr13:42071198 & Intron & 99.4 & 0.215 & 0.486 \\
\hline
\end{tabular}

Success rate means the call percentage of genotypes, HW, $P$ value of the $\chi^{2}$ test for Hardy-Weinberg equilibrium; MAF, minimal allele frequency.

\section{Gene expression assays}

Removed bone samples were extensively washed in PBS for eliminating blood and marrow contamination and were stored in liquid nitrogen. Human bone samples were cryoground under liquid nitrogen using a freezermill 6750 (SPEX Certiprep Inc., Metuchen, NJ, USA). Direct polyA-RNA was isolated with Dynabeads Oligo $(\mathrm{dT})_{25}$ paramagnetic particles (Dynal Biotech, Oslo, Norway) using the buffer set and protocol recommended by the manufacturer as it was previously described (27). After DNase treatment, mRNA was purified with NucleoSpin RNA Clean-up kit (Macherey-Nagel, Düren, Germany). The quantity and quality of mRNA were checked by spectrophotometry at $260 / 280 \mathrm{~nm}$. One hundred nanograms of human mRNA were reverse transcribed at $55^{\circ} \mathrm{C}$ using $200 \mathrm{U}$ Superscript III RNAse $\mathrm{H}$ reverse transcriptase (Invitrogen Life Technologies) with $125 \mathrm{ng}$ random hexamer (Promega) and $40 \mathrm{U}$ RNaseOUT Ribonuclease Inhibitor (Invitrogen Life Technologies) in 30- $\mu$ l reaction volumes. cDNAs for TNFRSF11B and TNFSF11 were amplified by quantitative real-time PCR in a $25-\mu l$ reaction volume containing $1 \mu \mathrm{l}$ cDNA, $12.5 \mu \mathrm{l}$ TaqMan $2 \times$ Universal PCR Master Mix NoAmpErase UNG, $1.25 \mu$ l predesigned and validated glyceraldehyde-3-phosphate (GAPDH) and TNFRSF11B- and TNFSF11-specific TaqMan gene expression assay $20 \times$ (Hs02758991_g1, Hs00900359_m1, and Hs00243519_m1) from Applied Biosystems (Foster City, CA, USA). ABI Prism 7500 RealTime PCR system was used to amplify the gene-specific cDNA from each sample in three parallel runs using a 96-well optical reaction plate following the protocol of 10 -min denaturation at $95^{\circ} \mathrm{C}$, and 50 cycles of 15 -s denaturation at $95^{\circ} \mathrm{C}, 1-\mathrm{min}$ annealing, and extension at $60{ }^{\circ} \mathrm{C}$. Housekeeping gene of GAPDH was used as endogenous control. Threshold cycle numbers were analyzed by Relative Quantification Study of 7500 System SDS Software 1.3. The relative quantity (RQ) of TNFRSF11B- and TNFSF11-specific mRNA was calculated from the averaged value of $\Delta C_{\mathrm{t}-\mathrm{s}}$.

\section{Statistical analysis}

Descriptive analyses of genotyped SNPs were performed using Haploview 4.0 software (28) (Table 3). Missing genotypes were imputed using a 10-nearest neighbor method (29). Kolmogorov-Smirnov test was applied to analyze the distribution of the study phenotypes. Stepwise regression analyses were applied to spine and total hip BMDs (linear regression) and nonvertebral osteoporotic fracture (logistic regression), as phenotypes, and age, menopausal age, body mass index (BMI), smoking status, and alcohol consumption as covariates were used to identify significant covariates with phenotypes. Spine and total hip BMD values were also entered into a logistic regression model to determine their influence on fracture risk. Computed regression residuals, representing covariate-adjusted study phenotypes, were used in subsequent analyses (30). Genotype-phenotype associations were tested in the three common genetic models (additive, dominant, and recessive) applying nonparametric tests (JonckheereTerpstra trend test for the additive model, as well as Mann-Whitney $U$ test for dominant and recessive models). To assess the reliability of the results, 10000 Monte Carlo permutations were performed to generate exact $P$ values. In individual analyses, permuted $P$ values were corrected with the number of the genotyped SNPs, thus here only results with a $P$ value of $<0.01$ were considered significant. The power of the study was calculated with the Quanto 1.1 software (31).

Haplotype analyses were performed using the 'haplo.stats' R-package (http://cran.r-project.org/). Score statistics were applied to test association between TNFSF11 haplotypes and study phenotypes. This method computes permuted $P$ values of the associations. Effect of haplotypes on covariate-adjusted study phenotypes was calculated in a generalized linear model (GLM) using the 'haplo.glm' function built in the software. Gene-gene interaction between the two genes was tested by performing multivariable linear regression analyses. Relative expression of TNFRSF11B and TNFSF 11 in bone tissue samples was compared between genotypes and haplotypes with nonparametric tests applying 10000 Monte Carlo permutations. Regression and nonparametric tests were performed using the SPSS for Windows, release 13.0.1 (SPSS Inc., Chicago, IL, USA). In haplotype, interaction, and gene expression studies, a $P$ value of $<0.05$ was considered nominally significant.

\section{Sequence analysis}

Genomic sequences of the regions next to the SNPs were obtained from the NCBI dbSNP database (http://www. ncbi.nlm.nih.gov/SNP/). Two sequences containing the 


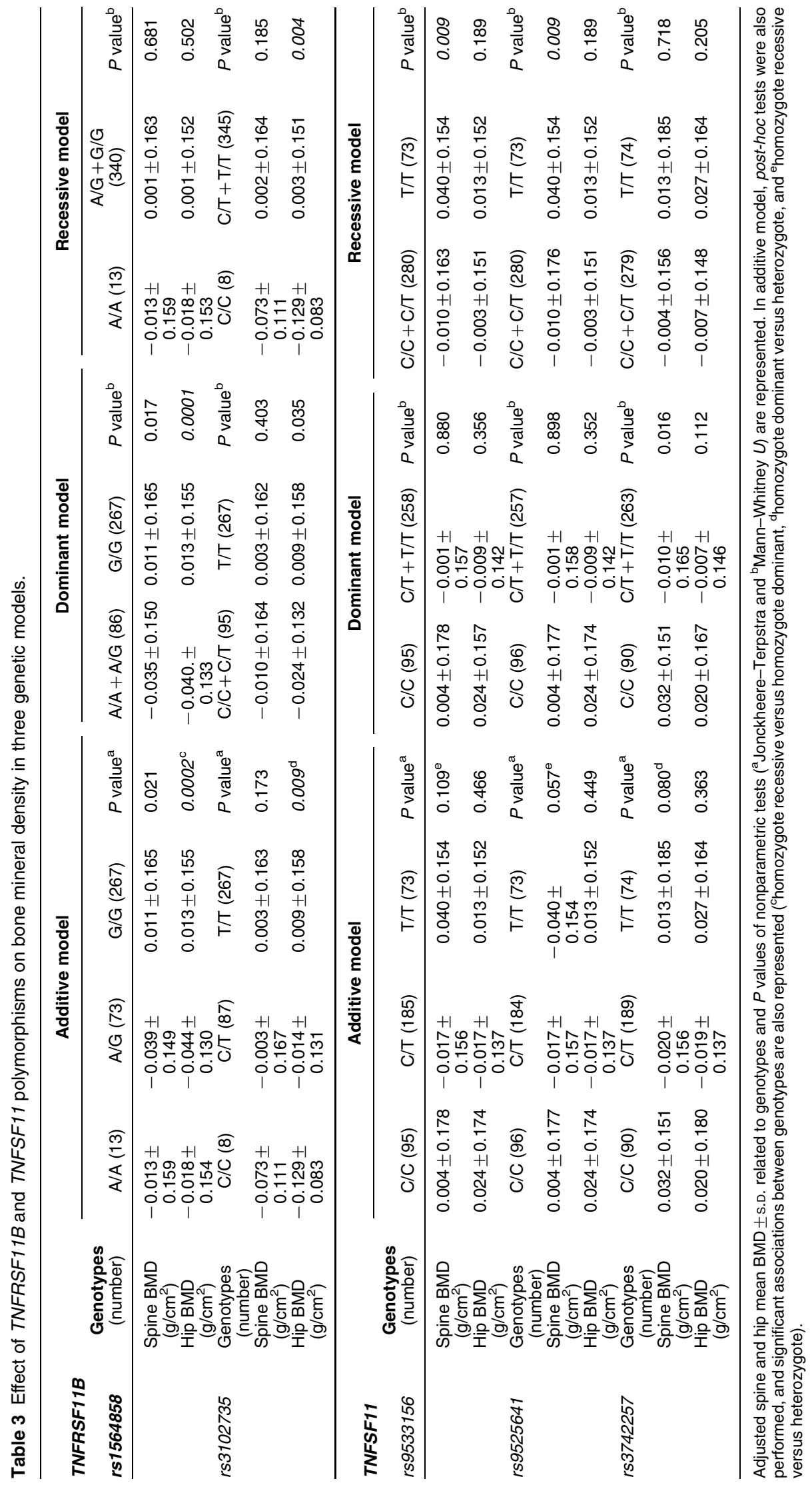


two allelic variants of each SNP were used to search for putative transcription factor binding sites in the TRANSFAC database using the PROMO web-based software (http://alggen.lsi.upc.es/).

\section{Results}

\section{Descriptive analyses}

The average age of the subjects whose gene expression was analyzed from the bone sample was $63.6 \pm 12.2$ years (no significant difference from the rest of the subjects, $P=0.29$ ). Other clinical parameters of this subgroup were not different either. Altogether, seven subjects were excluded from the statistical analyses because their genotyping success rate was lower than 4/5 SNPs. The reproducibility of the high-throughput genotyping method called SNPstream was $100 \%$ in our study (genotypes were the same in each parallel run). The overall success rate of genotyping process was $99.7 \%$, only five missing genotypes were imputed in the final database. All the genotyped SNPs were in Hardy-Weinberg equilibrium, and the minimal allele frequency was higher than $5 \%$ in each case. Linkage disequilibrium was also determined in Haploview. The three SNPs (rs9533156, rs9525641, and rs3742257) of TNFSF11 were in almost complete LD constructing a haploblock, while the two SNPs of TNFRSF11B were not significantly linked with each other. Age, menopausal age, and BMI proved to be significant covariates of $\mathrm{BMD}$ in the regression model. Fracture risk was significantly influenced by age, BMI, and BMD. The power of the study was higher than $75 \%$ (0.75) for hip BMD (mean \pm s.D.: $0.785 \pm 0.168)$ at a significance level of 0.05 , MAF of 0.140 , and 353 individuals to detect a difference in $\mathrm{BMD}$ of $0.054 \mathrm{~g} / \mathrm{cm}^{2}$ under the dominant model. For spine BMD (mean \pm s.D.: $0.887 \pm 0.176)$ and MAF of 0.460 , there would be a power of $65 \%$ to detect a difference of $0.053 \mathrm{~g} / \mathrm{cm}^{2}$ under the recessive model.

\section{Association analyses}

Table 3 shows the distribution of genotypes and the unadjusted mean BMD \pm s.D. values. Permuted $P$ values are also presented for the three genetic models. TNFRSF11B polymorphisms were significantly associated with the spine and hip BMDs. Carriers of the 'A' allele of rs1564858 had significantly lower BMD at the hip in the dominant model (covariate-adjusted differences in $\mathrm{BMD} \pm$ s.D. were $-0.040 \pm 0.133 \mathrm{~g} / \mathrm{cm}^{2}$ for ' $\mathrm{A} / \mathrm{A}+\mathrm{A} / \mathrm{G}$ ' and $0.013 \pm 0.155 \mathrm{~g} / \mathrm{cm}^{2}$ for ' $\mathrm{G} / \mathrm{G}$ ' genotypes at the hip, $P=0.0001)$. The $r s 3102735$ was significantly related to hip BMD in the recessive model (adjusted hip BMD \pm s.D. values were $-0.129 \pm 0.083$ and $0.003 \pm 0.151$ in the cases of ' $\mathrm{C} / \mathrm{C}$ ' and ' $\mathrm{C} / \mathrm{T}+\mathrm{T} / \mathrm{T}$ ' genotypes, $P=0.004)$. Two SNPs of TNFSF11 were significantly associated with spine BMD (adjusted spine BMD \pm s.D. values were $-0.010 \pm 0.163$ and $0.040 \pm 0.154$ in the groups of ' $\mathrm{C} / \mathrm{C}+\mathrm{C} / \mathrm{T}$ ' and ' $\mathrm{T} / \mathrm{T}$ ' of the two strongly linked rs9533156 and rs9525641). None of the studied SNPs were related to nonvertebral fractures.

The gene-gene interaction analyses did not show any significant interaction between the studied SNPs of the two genes.

\section{Haplotype analyses}

We performed score tests and GLMs to analyze the association between the TNFSF11 haplotypes and $\mathrm{BMD}$ as well as nonvertebral fracture risk (Table 4). The TNFSF11 haplotypes proved to be significantly associated with spine BMD (permuted global $P=0.022$

Table 4 Effects of TNFSF11 haplotypes on adjusted spine BMD and TNFRSF11B haplotypes on adjusted hip BMD.

\begin{tabular}{|c|c|c|c|c|c|}
\hline \multirow[b]{2}{*}{ Haplotypes } & \multirow[b]{2}{*}{ Frequencies } & \multicolumn{2}{|c|}{ Score test } & \multicolumn{2}{|c|}{ GLM model } \\
\hline & & Hap score & $P$ value ${ }^{\mathrm{a}}$ & Coefficient \pm S.E.M. & $P$ value $^{\mathrm{b}}$ \\
\hline \multicolumn{6}{|c|}{ (A) Effect of TNFSF11 haplotypes on adjusted spine BMD } \\
\hline TTC & 0.453 & -0.398 & 0.711 & $0.037 \pm 0.019$ & 0.048 \\
\hline CCC & 0.063 & -0.428 & 0.679 & $-0.025 \pm 0.028$ & 0.423 \\
\hline \multirow[t]{2}{*}{ CCT } & 0.471 & -2.432 & 0.013 & $-0.049 \pm 0.021$ & 0.018 \\
\hline & & \multicolumn{2}{|c|}{ Score test } & \multicolumn{2}{|c|}{ GLM model } \\
\hline Haplotypes & Frequencies & Hap score & $P$ value ${ }^{\mathrm{a}}$ & Coefficient \pm S.E.M. & $P$ value $^{\mathrm{c}}$ \\
\hline \multicolumn{6}{|c|}{ (B) Effect of TNFRSF11B haplotypes on adjusted hip BMD } \\
\hline GT & 0.789 & 2.846 & 0.006 & $0.016 \pm 0.010$ & 0.102 \\
\hline $\mathrm{GC}$ & 0.069 & -1.182 & 0.245 & $-0.034 \pm 0.023$ & 0.138 \\
\hline AT & 0.063 & -1.487 & 0.148 & $-0.037 \pm 0.022$ & 0.106 \\
\hline $\mathrm{AC}$ & 0.078 & -1.987 & 0.041 & $-0.044 \pm 0.021$ & 0.039 \\
\hline
\end{tabular}

Haplotypes with a frequency $>5 \%$ and their effect on covariate-adjusted spine BMD are represented. 'Permuted $P$ value of global association was 0.022 ; ' 'GT' haplotype was entered into the GLM as reference haplotype, and $P$ values of the GLM sign the significance of $t$-statistic of regression variables characterized by the estimated regression coefficients and their standard errors; ' 'TTC' haplotype was entered into the GLM as reference haplotype, and $P$ values of the GLM sign the significance of $t$-statistic of regression variables characterized by the estimated regression coefficients and their standard errors; ${ }^{d}$ permuted $P$ value of global association was 0.065 . 
under dominant model). The common 'CCT' haplotype was related to low BMD either in score test or in GLM, while the other common haplotype 'TTC' correlated with increased BMD at the spine. The global association between the TNFRSF11B haplotypes and study phenotypes was not significant, but two haplotypes have shown significant individual effect on hip BMD (Table 4). The most common 'GT' haplotype was significantly associated with high hip BMD, while a rare haplotype 'AC' was related to low hip BMD in the haplotype analysis. We did not find significant association with nonvertebral fractures.

\section{Gene expression assay}

The quantitative real-time PCR was successfully performed in 16 bone samples, and mRNA was degraded in one sample. The relative expression of TNFSF11-specific mRNA seemed to be dependent on the number of 'CCT' haplotype (Fig. 1) (permuted $P$ value of global association was 0.007). In subjects with one or two copies of 'CCT' haplotype, TNFSF11 expression was significantly 2.25-fold increased compared to those with no 'CCT' haplotype (mean RQ \pm s.D. values were $0.126 \pm 0.050$ and $0.056 \pm 0.026$ in 'CCT' carriers and noncarriers respectively, $P=0.025$ ). No correlation was found between gene-specific mRNA expression and TNFRSF11B genotypes.

We performed 'in silico' sequence analysis to identify whether changes in mRNA levels according to haplotypes could be associated with the different transcription factor (TF) binding profile of the TNFSF11 promoter. A putative binding site of seven different TFs was identified in the promoter region of 'CCT' haplotype, while only two haplotype-specific TF binding sites were seen in the other common haplotype, 'TTC'.

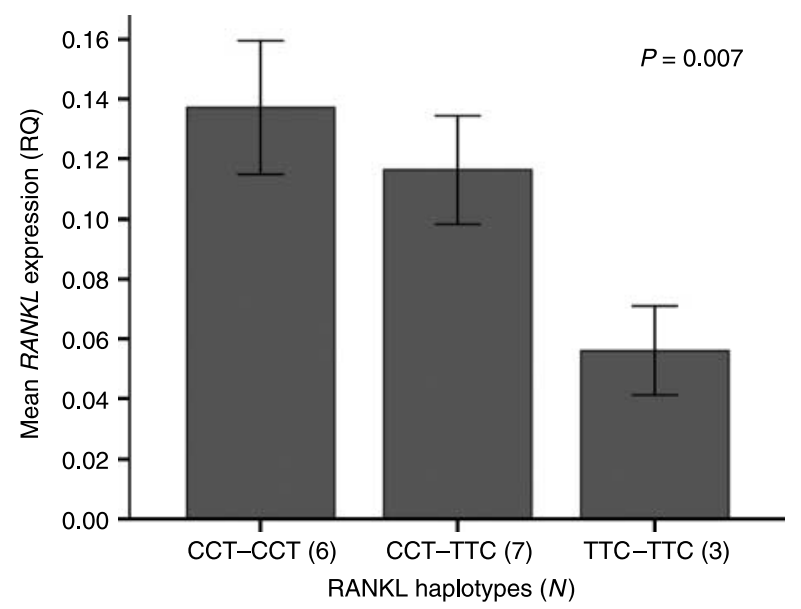

Figure 1 Quantitative expression of RANKL depending on RANKL haplotypes. Bars represent the mean \pm S.E.M. of the relative expression (RQ) of the RANKL gene to GAPDH in the three haplotype groups. Number of carriers in each group and permuted $P$ value of the global association are also represented.

\section{Discussion}

In this study, we have investigated SNPs and haplotypes in the TNFRSF 11B/TNFSF 11 genes exhibiting a significant correlation with BMD at the spine and hip. Furthermore, we have shown that increased tissue mRNA expression in subjects carrying 'CCT' TNFSF11 haplotype was associated with reduced BMD.

Bone resorption process is influenced by the TNFSF11/TNFRSF11B ratio. Increase in this ratio is mainly due to the increase in TNFSF 11 gene expression (24). The TNFSF11 gene is a member of the TNF superfamily localized at 13q14, with eight exons. Mutations in the gene lead to an osteoclast-poor form of osteopetrosis in humans (32). Promoter SNPs of the TNFSF 11 gene are good candidates for the genetic regulation of BMD. While studying rs9533156 and rs9525641 SNPs in the promoter region of TNFSF11 gene, Mencej et al. (24) found both polymorphisms to be associated with hip BMD, and later (25) with lumbar spine BMD. We could confirm their results, and in addition, we have firstly identified a third SNP in an intronic region of TNFSF11 gene showing an association with spine BMD as well as a strong linkage with the other two SNPs. The latter fact provides a rationale for examining the relationship between the haplotypes of these SNPs and BMD.

Mencej et al. (24) studied a haplotype consisting of three SNP alleles where the third SNP (rs9533155) was also located in the promoter of the TNFSF11 gene. Subjects with the 'CCG' haplotype had decreased spine BMD. They also transfected human embryonic kidney cells (HEK 293) with amplified fragments of different haplotypes. Increased TNFSF11 expression could be seen in 'CCG' haplotype by this method. Using rs3742257 SNP as part of the new haplotype examined in our study, we demonstrated for the first time in the literature that elevated TNFSF 11 expression in human bone samples is associated with 'CCT' haplotype. In this case, the new element of the haplotype was coming from an intronic SNP being in strong linkage with the promoter region SNPs. The same subjects with 'CCT' haplotype exhibited reduced BMD, which was possibly a consequence of increased TNFSF11 expression resulting in stimulated osteoclast activity. The presumable role of the intronic SNP was shown in haplotype analyses where only 'CCT' haplotype and not 'CCC' haplotype was associated with lower BMD. We also performed the TNFSF11 haplotype analysis using the two common SNPs (rs9533156 and rs9525641) without the third one (rs3742257) representing the effect of the promoter haplotypes of TNFSF11 on study phenotypes (data not shown). 'TT' haplotypes of the two SNPs were significantly associated with higher BMD $(P=0.003)$, while global association was also significant in the score test $\left(P_{\text {global }}=0.010\right)$. These results show - according to Mencej et al. - those promoter variants of the TNFSF11 that have a significant effect on BMD. However, in our 
three-SNP haplotype analyses, the 'CC' promoter haplotype resulted in a significantly lower spine BMD only in combination with the ' $\mathrm{T}$ ' allele of the third genotyped SNP (rs3742257), suggesting that besides the promoter, the other region tagged by the rs3742257 could play a potential role in the association between the genetic variants of the TNFSF11 and BMD.

TNFSF11 expression is controlled by various transcription factors, cytokines, and hormones (33). The promoter region SNPs could influence the binding of these regulators, and thus, gene expression. Our 'in silico' search for binding sites in the promoter region of TNFSF11 gene resulted in a difference according to haplotypes. 'CCT' haplotype could potentially bind seven haplotype-specific transcriptional factors in contrast to 'TTC' that could bind only two. This difference might be reflected in the altered expressional activity of the different haplotypes.

The association of rs3102735 in TNFRSF $11 B$ gene with bone metabolism is very contradictory. It was identified in the promoter region by Kusk (34). In their study, postmenopausal women carrying the ' $G$ ' allele had lower bone mass than women homozygotic for the 'A' allele. Langdahl et al. (14) have shown the ' $G$ ' allele to be more common in osteoporotic patients. Their regression analyses revealed that this polymorphism predicts bone mass and tends to predict osteoporotic fractures independently of BMD. Jorgensen et al. (13) have found a significant influence of this mutation on bone mass and fracture status independently of serum TNFRSF11B level. Our results confirm these positive findings. We found an association between the rs3102735 polymorphism and BMD, but did not find any effect on the fracture risk; however, the present study was underpowered to show small effects. Other authors $(16,17,35)$ have reported no effect of this genetic variation on BMD. There are several possible explanations for these discrepancies. BMD and fracture risk are complex traits, and the contribution of a single gene is expected to be relatively small and is influenced by other genes and environmental factors. Inconsistency in results could therefore arise from differences in the ethnic background, age, calcium intake, and sites of BMD measurements. In our study, no detectable influence of this promoter SNP on in vivo gene expression of TNFRSF11B was observed, and this SNP appeared not to affect any recognition sites for known transcription factors based on 'in silico' sequence analysis. Our results suggest that this SNP could be a marker of the altered gene function rather than a direct contributor.

The rs1564858 SNP, located in the second intron of the TNFRSF $11 B$ gene, was significantly associated with hip BMD; however, it is not in linkage disequilibrium with the rs3102735 polymorphism. This fact raises the possible genetic importance of both SNPs in bone metabolism. No effect on the TNFRSF11B expression was seen depending on TNFRSF11B genotypes. This could be explained by the fact that rs 1564858 lies in an intronic region, and 'in silico' data indicate that it is located in a splice site of the gene, suggesting a possible indirect role of this SNP in the regulation of gene function. The heterozygote genotype of this SNP was significantly associated with the lowest BMD. This could be explained by the phenomenon of molecular heterosis. Molecular heterosis occurs when subjects for a polymorphism show a significantly greater or lesser effect for a trait than homozygotes. Regarding this TNFRSF11B polymorphism, molecular heterosis could be a result of the post-transcriptomic changes in the TNFRSF11B-specific mRNA that might be caused by this SNP. Further studies need to clarify the exact role of this region. Common haplotype constructed by the two SNPs of the TNFRSF11B gene seemed to be related to higher hip BMD, while a less common one was associated with lower BMD, which also underline the importance of the genetic variations of TNFRSF11B in OP. Nevertheless, this result should be handled with some caution since the global association of TNFRSF11B haplotypes and hip BMD was not significant in our model. This apparent controversy can be explained by the possibility that these two SNPs did not construct a haploblock inside the gene. In general, haplotype estimation processes are more reliable when minor genotype frequency is more than $10 \%$.

Considering the well-known biological relation of the two molecules, we studied the gene-gene interaction between the SNPs of the TNFRSF $11 B$ and TNFSF 11 genes. We did not find any significant interaction among the genotyped polymorphisms. There are two possible explanations for this result. The biological interaction of the two molecules could arise from a posttranscriptomic modification, and/or the real genetic interaction might occur between other genomic regions than we studied here.

There are several potential limitations to this study. First, the study population comprised women who visited a university hospital and they may not have been representative of the general population residing in a community, thus possibly resulting in selection bias. Secondly, we investigated only five SNPs and did not screen two genes for the biologically active loci. Thirdly, power of the study for fracture risk was low $(<50 \%)$ due to the sample size, and we did not study the vertebral compression fracture. Lastly, similar to any other candidate gene studies on complex diseases/traits, this work only reveals part of the whole genetic architecture underlying the etiology of OP. Our study also has a few strengths. Our subjects were ethnically homogenous. We applied statistical procedures with permutation tests to reduce population-based bias. Also, this is the first study to evaluate the TNFSF11/TNFRSF11B signaling system haplotype effects on gene expression in human bone samples.

In summary, we have found a significant correlation between TNFSF11 and TNFRSF11B genotypes and BMD. Also, we are the first to show a new TNFSF11 
haplotype (CCT) that is associated with increased in vivo TNFSF11 expression in human bone tissue as well as with reduced BMD in Hungarian postmenopausal women. The importance of these findings deserves further investigations.

\section{Declaration of interest}

The authors declare that there is no conflict of interest that could be perceived as prejudicing the impartiality of the research reported.

\section{Funding}

This work was supported by grants NKFP-1A/007/2004 and NKFP1A/002/2004 from the National Research and Technological Office (NKTH) of Hungary, as well as by research grant ETT 022/2006 from the Ministry of Health, Hungary. J Kiss was supported by OTKA grant no. T-037436.

\section{References}

1 Consensus development conference: diagnosis, prophylaxis and treatment of osteoporosis. American Journal of Medicine 199394 646-650.

2 Hansen MA, Overgaard K, Riis BJ \& Christiansen C. Role of peak bone mass and bone loss in postmenopausal osteoporosis: 12 years study. BMJ 1991303 961-964.

3 Ralston SH. Genetic control of susceptibility to osteoporosis. Journal of Clinical Endocrinology and Metabolism 200287 2460-2466.

4 Makovey J, Nguyen TV, Naganathan V, Wark JD \& Sambrook PN. Genetic effects on bone loss in peri- and postmenopausal women: a longitudinal twin study. Journal of Bone and Mineral Research 2007 22 1773-1780.

5 Ralston SH. Genetics of osteoporosis. Proceedings of the Nutrition Society 200766 158-165.

6 Simonet WS, Lacey DL, Dunstan CR, Kelley M, Chang MS, Luthy R, Nguyen HQ, Wooden S, Bennett L, Boone T, Shimamoto G, DeRose M, Elliott R, Colombero A, Tan HL, Trail G, Sullivan J, Davy E, Bucay N, Renshaw-Gegg L, Hughes TM, Hill D, Pattison W, Campbell P, Sander S, Van G, Tarpley J, Derby P, Lee R \& Boyle WJ. Osteoprotegerin: a novel secreted protein involved in the regulation of bone density. Cell 199789 309-319.

7 Yasuda H, Shima N, Nakagawa N, Yamaguchi K, Kinosaki M, Mochizuki S, Tomoyasu A, Yano K, Goto M, Murakami A, Tsuda E, Morinaga T, Higashio K, Udagawa N, Takahashi N \& Suda T. Osteoclast differentiation factor is a ligand for osteoprotegerin/ osteoclastogenesis-inhibitory factor and is identical to TRANCE/ RANKL. PNAS 199895 3597-3602.

8 Teitelbaum SL \& Ross FP. Genetic regulation of osteoclast development and function. Nature Reviews. Genetics 20034 638-649.

9 Aubin JE \& Bonnelye E. Osteoprotegerin and its ligand: a new paradigm for regulation of osteoclastogenesis and bone resorption. Osteoporosis International 200011 905-913.

10 Hofbauer LC. Osteoprotegerin ligand and osteoprotegerin: novel implications for osteoclast biology and bone metabolism. European Journal of Endocrinology 1999141 195-210.

11 Hofbauer LC, Khosla S, Dunstan CR, Lacey DL, Boyle WJ \& Riggs BL. The roles of osteoprotegerin and osteoprotegerin ligand in the paracrine regulation of bone resorption. Journal of Bone and Mineral Research 200015 2-12.

12 Arko B, Prezelj J, Komel R, Kocijancic A, Hudler P \& Marc J. Sequence variations in the osteoprotegerin gene promoter in patients with postmenopausal osteoporosis. Journal of Clinical Endocrinology and Metabolism 200287 4080-4084.
13 Jorgensen HL, Kusk P, Madsen B, Fenger M \& Lauritzen JB. Serum osteoprotegerin (OPG) and the A163G polymorphism in the OPG promoter region are related to peripheral measures of bone mass and fracture odds ratios. Journal of Bone and Mineral Metabolism 200422 132-138.

14 Langdahl BL, Carstens M, Stenkjaer L \& Eriksen EF. Polymorphisms in the osteoprotegerin gene are associated with osteoporotic fractures. Journal of Bone and Mineral Research 2002 17 1245-1255.

15 Yamada Y, Ando F, Niino N \& Shimokata H. Association of polymorphisms of the osteoprotegerin gene with bone mineral density in Japanese women but not men. Molecular Genetics and Metabolism 200380 344-349.

16 Garcia-Unzueta MT, Riancho JA, Zarrabeitia MT, Sanudo C, Berja A, Valero C, Pesquera C, Paule B, Gonzalez-Macias J \& Amado JA. Association of the $163 \mathrm{~A} / \mathrm{G}$ and $1181 \mathrm{G} / \mathrm{C}$ osteoprotegerin polymorphism with bone mineral density. Hormone and Metabolic Research 200840 219-224.

17 Kim JG, Kim JH, Kim JY, Ku SY, Jee BC, Suh CS, Kim SH \& Choi YM. Association between osteoprotegerin (OPG), receptor activator of nuclear factor-kappaB (RANK), and RANK ligand (RANKL) gene polymorphisms and circulating OPG, soluble RANKL levels, and bone mineral density in Korean postmenopausal women. Menopause 200714 913-918.

18 Richards JB, Rivadeneira F, Inouye M, Pastinen TM, Soranzo N, Wilson SG, Andrew T, Falchi M, Gwilliam R, Ahmadi KR, Valdes AM, Arp P, Whittaker P, Verlaan DJ, Jhamai M, Kumanduri V, Moorhouse M, van Meurs JB, Hofman A, Pols HAP, Hart D, Zhai G, Kato BS, Mullin BH, Zhang F, Deloukas P, Uitterlinden AG \& Spector TD. Bone mineral density, osteoporosis, and osteoporotic fractures: a genome-wide association study. Lancet 2008371 1505-1512.

19 Styrkarsdottir U, Halldorsson BV, Gretarsdottir S, Gudbjartsson DF, Walters GB, Ingvarsson T, Jonsdottir T, Saemundsdottir J, Center JR, Nguyen TV, Bagger Y, Gulcher JR, Eisman JA, Christiansen C, Sigurdsson G, Kong A, Thorsteinsdottir U \& Stefansson K. Multiple genetic loci for bone mineral density and fractures. New England Journal of Medicine 2008358 2355-2365.

20 Hsu H, Lacey DL, Dunstan CR, Solovyev I, Colombero A, Timms E, Tan HL, Elliott G, Kelley MJ, Sarosi I, Wang L, Xia XZ, Elliott R, Chiu L, Black T, Scully S, Capparelli C, Morony S, Shimamoto G, Bass MB \& Boyle WJ. Tumor necrosis factor receptor family member RANK mediates osteoclast differentiation and activation induced by osteoprotegerin ligand. PNAS 199996 3540-3545.

21 Kim N, Odgren PR, Kim DK, Marks SC Jr \& Choi Y. Diverse roles of the tumor necrosis factor family member TRANCE in skeletal physiology revealed by TRANCE deficiency and partial rescue by a lymphocyteexpressed TRANCE transgene. PNAS 200097 10905-10910.

22 Lacey DL, Timms E, Tan HL, Kelley MJ, Dunstan CR, Burgess T, Elliott R, Colombero A, Elliott G, Scully S, Hsu H, Sullivan J, Hawkins N, Davy E, Capparelli C, Eli A, Qian YX, Kaufman S, Sarosi I, Shalhoub V, Senaldi G, Guo J, Delaney J \& Boyle WJ. Osteoprotegerin ligand is a cytokine that regulates osteoclast differentiation and activation. Cell 199893 165-176.

23 Hsu Y-H, Niu T, Terwedow HA, Xu X, Feng Y, Li Z, Brain JD, Rosen CJ, Laird N \& Xu X. Variation in genes involved in the RANKL/RANK/OPG bone remodeling pathway are associated with bone mineral density at different skeletal sites in men. Human Genetics 2006118 568-577.

24 Mencej S, Prezelj J, Kocijancic A, Ostanek B \& Marc J. Association of TNFSF11 gene promoter polymorphisms with bone mineral density in postmenopausal women. Maturitas 200655 219-226.

25 Mencej S, Albagha OME, Prezelj J, Kocjan T \& Marc J. Tumour necrosis factor superfamily member 11 gene promoter polymorphisms modulate promoter activity and influence bone mineral density in postmenopausal women with osteoporosis. Journal of Molecular Endocrinology 200840 273-279.

26 Fardellone P, Sebert JL, Bouraya M, Bonidan O, Leclercq G, Doutrellot C, Bellony R \& Dubreuil A. Evaluation of the calcium content of diet by frequential self-questionnaire. Revue $d u$ Rhumatisme et des Maladies Osteo-Articulaires $19915 \mathbf{5 8} 99-103$. 
27 Balla B, Kosa JP, Kiss J, Borsy A, Podani J, Takacs I, Lazary A, Nagy Z, Bacsi K, Speer G, Orosz L \& Lakatos P. Different gene expression patterns in the bone tissue of aging postmenopausal osteoporotic and non-osteoporotic women. Calcified Tissue International $2008 \mathbf{8 2} 12-26$.

28 Barrett JC, Fry B, Maller J \& Daly MJ. Haploview: analysis and visualization of LD and haplotype maps. Bioinformatics 200521 263-265.

29 Xie Q, Ratnasinghe LD, Hong H, Perkins R, Tang Z-Z, Hu N, Taylor PR \& Tong W. Decision forest analysis of 61 single nucleotide polymorphisms in a case-control study of esophageal cancer; a novel method. BMC Bioinformatics $20056 \mathrm{~S} 4$.

30 Foroud T, Ichikawa S, Koller D, Lai D, Curry L, Xuei X, Edenberg HJ, Hui S, Peacock M \& Econs MJ. Association studies of ALOX 5 and bone mineral density in healthy adults. Osteoporosis International $200819637-643$.

31 Purcell S, Cherny SS \& Sham PC. Genetic Power Calculator: design of linkage and association genetic mapping studies of complex traits. Bioinformatics 200319 149-150.
32 Sobacchi C, Frattini A, Guerrini MM, Abinun M, Pangrazio A, Susani L, Bredius R, Mancini G, Cant A, Bishop N, Grabowski P, Del Fattore A, Messina C, Errigo G, Coxon FP, Scott DI, Teti A, Rogers MJ, Vezzoni P, Villa A \& Helfrich MH. Osteoclast-poor human osteopetrosis due to mutations in the gene encoding RANKL. Nature Genetics 200739 960-962.

33 Hofbauer LC \& Heufelder AE. Role of receptor activator of nuclear factor-kappaB ligand and osteoprotegerin in bone cell biology. Journal of Molecular Medicine 2001 79 243-253.

34 Kusk P. International patent C12Q1/68. Publication number WO 00/422162000.

35 Ueland T, Bollerslev J, Wilson SG, Dick IM, Islam FMA, Mullin BH, Devine A \& Prince RL. No associations between OPG gene polymorphisms or serum levels and measures of osteoporosis in elderly Australian women. Bone 200740 175-181.

Received 9 November 2009

Accepted 24 November 2009 